\title{
Eco-architecture and sustainable mobility: an integrated approach in Ladispoli town
}

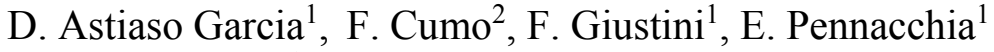 \\ \& A. M. Fogheri ${ }^{1}$ \\ ${ }^{1}$ DIAEE, Department of Astronautical, Electrical and Energy \\ Engineering, Sapienza University of Rome, Italy \\ ${ }^{2}$ CITERA, Interdepartmental Centre for Territory, Building, Conservation \\ and Environment, Sapienza University of Rome, Italy
}

\begin{abstract}
This paper presents an eco-architecture project in a public green space of the Ladispoli Municipality, located on the Italian shorelines close to the city of Rome.

The purpose of the project is the creation of a multifunctional urban green space, where social relations, sports, environmental awareness education and other activities can take place in a natural context. The final aim of the project, which includes a requalification of the surrounding areas, is to obtain an ecofriendly interaction between the urban public space and the built space, with sustainable mobility principles and the conservation of the natural environment.

The project offers different outdoor activities for all ages and includes the design of a building which contains two multipurpose playgrounds, a gym, supporting functions, a bar and public toilets.

The building design includes a green roof, for preserving space to nature and for guaranteeing a harmonious integration with the surrounding environment.

In order to enlarge the green area, to bring it up to the contiguous buildings and to create a closer connection between the housing areas on both sides of the ditch and the park itself, a tunnel for the vehicular traffic was created.

The project improves the usability of the green space through the introduction of: pedestrian and cycle paths connected to the existing ones, wooden bridges, new functions and services.

The distinctive feature of the whole project is an integration of different best available technologies for obtaining an optimization of the performances in
\end{abstract}


terms of energy efficiency and environmental sustainability, aiming to achieve at the same time, a reduction of operating costs and the preservation of local biodiversity.

Keywords: environmental sustainability, urban green areas management, best available techniques, eco-friendly buildings.

\section{Introduction}

Reshaping urban areas, high performing architecture for the community and spread of new technologies are some of the essential elements for the development of smart cities and communities. Moreover, these elements are aimed at improving the quality of life of the community operating in the major urban contexts which include mobility, health, education and culture, tourism, energy and smart grids management, jointly with the protection of natural resources. The project responds to the requirements of improving energy efficiency, sustainable buildings and mobility systems [1], as well as of the enhancement of spaces and public facilities and the implementation of ecological corridors in an urban areas.

This project has been implemented using the first results coming from the European project GREAT Med, of which the Sapienza University of Rome is the main applicant, and the municipality of Ladispoli is a network member.

Precisely because of the importance assumed by green areas in urban context, the project is placed in a central park for public use, of approximately $30,000 \mathrm{~m}^{2}$ near the center of the city (Fig. 1).

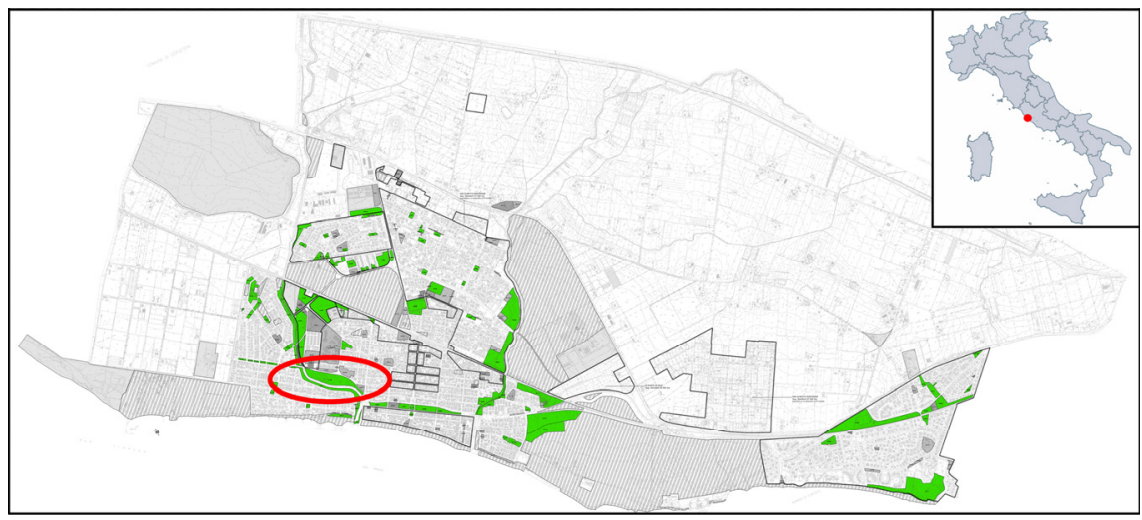

Figure 1: Urban green areas in Ladispoli Municipality: circled, the project area.

The concept of the redevelopment project is to symbolically bring to light the ancient origins of the place: Alsium, the Etruscan port city, through the creation of paths and benches that recall the stylized drawing of the waves depicted on Etruscan furniture and crockery (Figs 2-3). 


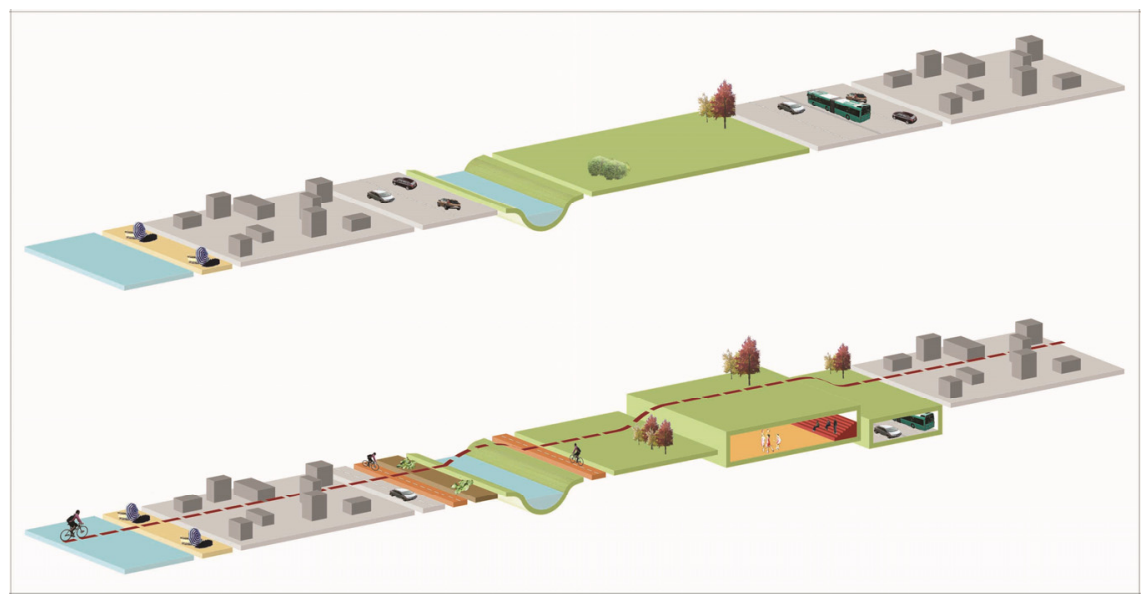

Figure 2: Conceptual scheme of the area, before and after the redevelopment project.

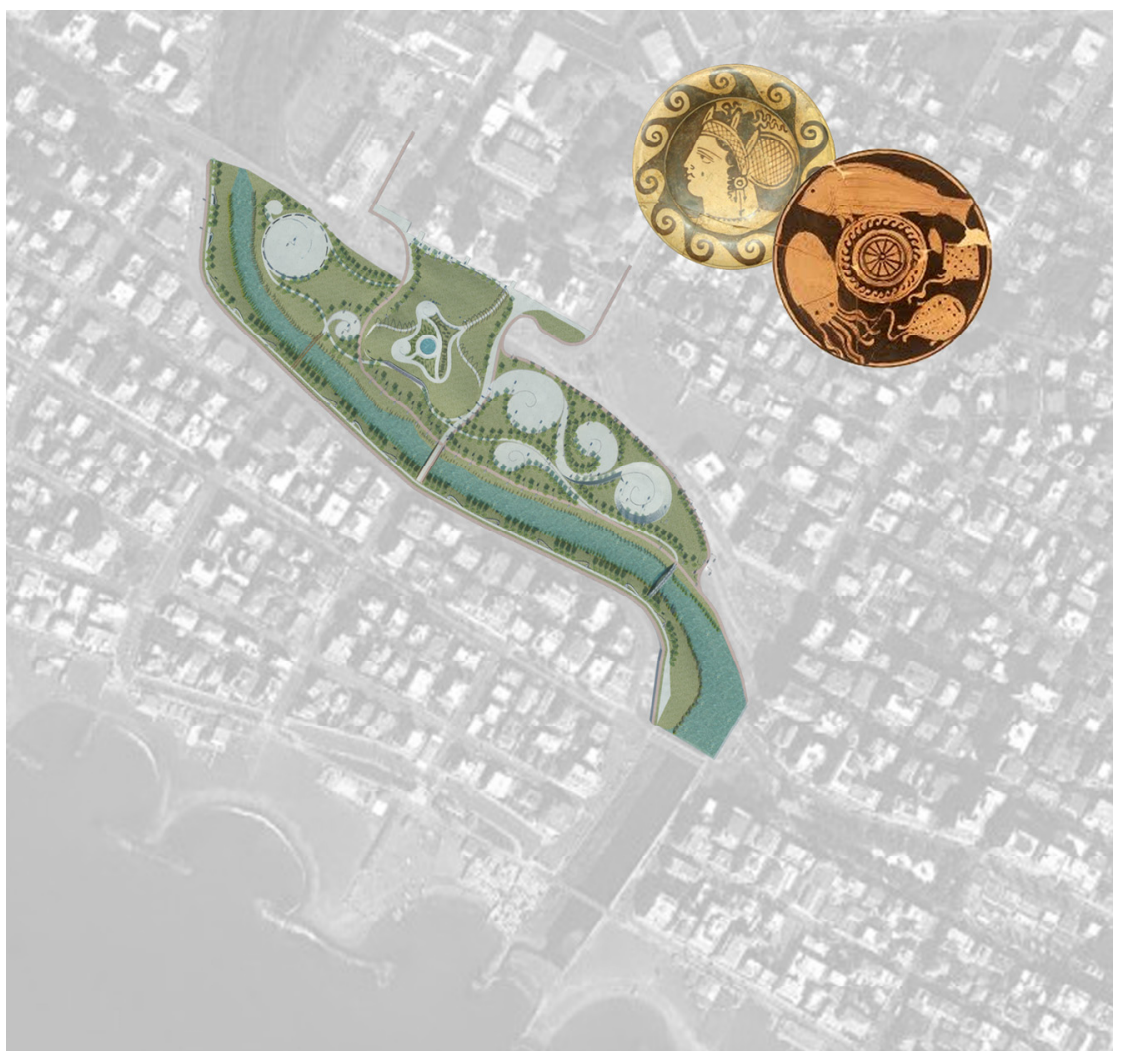

Figure 3: Project design map in a satellite image and examples of Etruscan furniture for the concept of the project design. 


\section{Architectural interventions and technologies used}

The project offers to the city a collective space for social relationships and activities connected with nature. It is designed for restoring the identity of the space and to create an interaction between collective open areas, built environment and nature [2] (Fig. 4).

Generally the project design applies the main principles of environmental conservation and ecological sustainability in the design of modern buildings, based on resource-efficient technologies and green architecture designs [3, 4].

Considering the functional point of view, the selected area is critical for the improvement of the sustainable mobility: pedestrian paths, cycle paths and two wheels electric mobility.

The green area requalification also involves some pre-existing sport facilities: in the park itself, there were two outdoor playgrounds that actually are included in the project and put indoor, in order to enjoy them throughout the whole year.

In particular, the sports center designed contains two multipurpose playgrounds, a gym, supporting functions, a bar and public toilets (Fig. 5).

The building has a green roof that creates a connection between the park and the building itself.

The fourth side, in front of the river, hosting the entry of the sport centre, is characterised by a glass wall that allows a natural lightening.

The structure respects the principles of sustainable design and low energy performance $[5,6]$, as it is built using local materials and the best available technologies for envelope and HVAC plants [7].

On the semi extensive green roof there is a sensory path designed to create a little oasis with a mosaic of water, flowers fragrances and colours (Figure 6A). Indigenous species plants and flowers with special fragrances have been chosen for this path: lavender, mint, Lamiaceae (thyme and sage), broom, lemon balm.

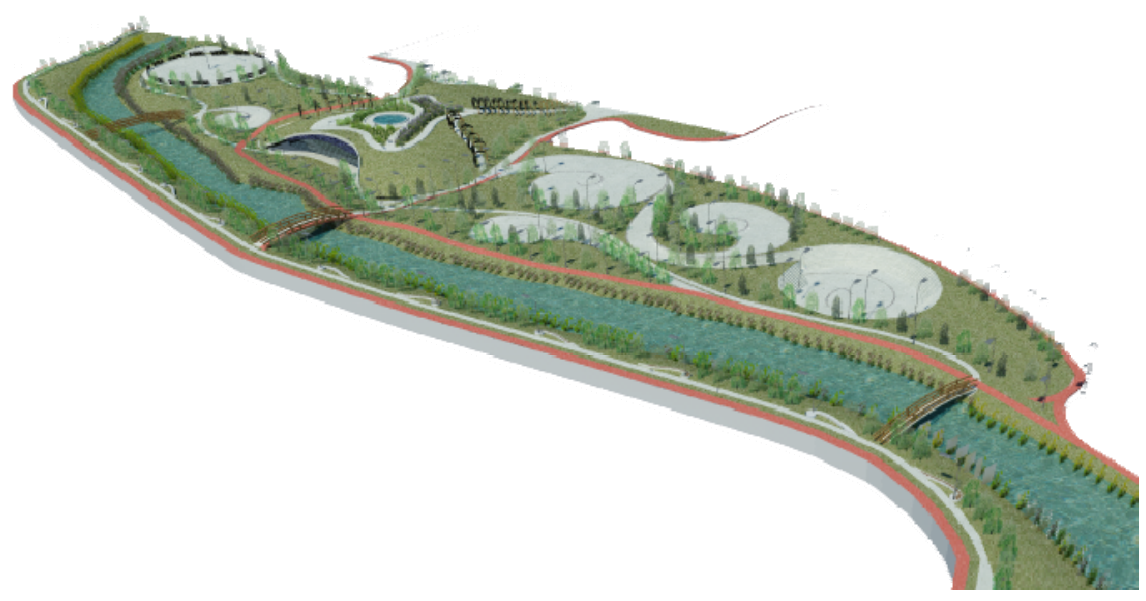

Figure 4: Perspective view of the park. 

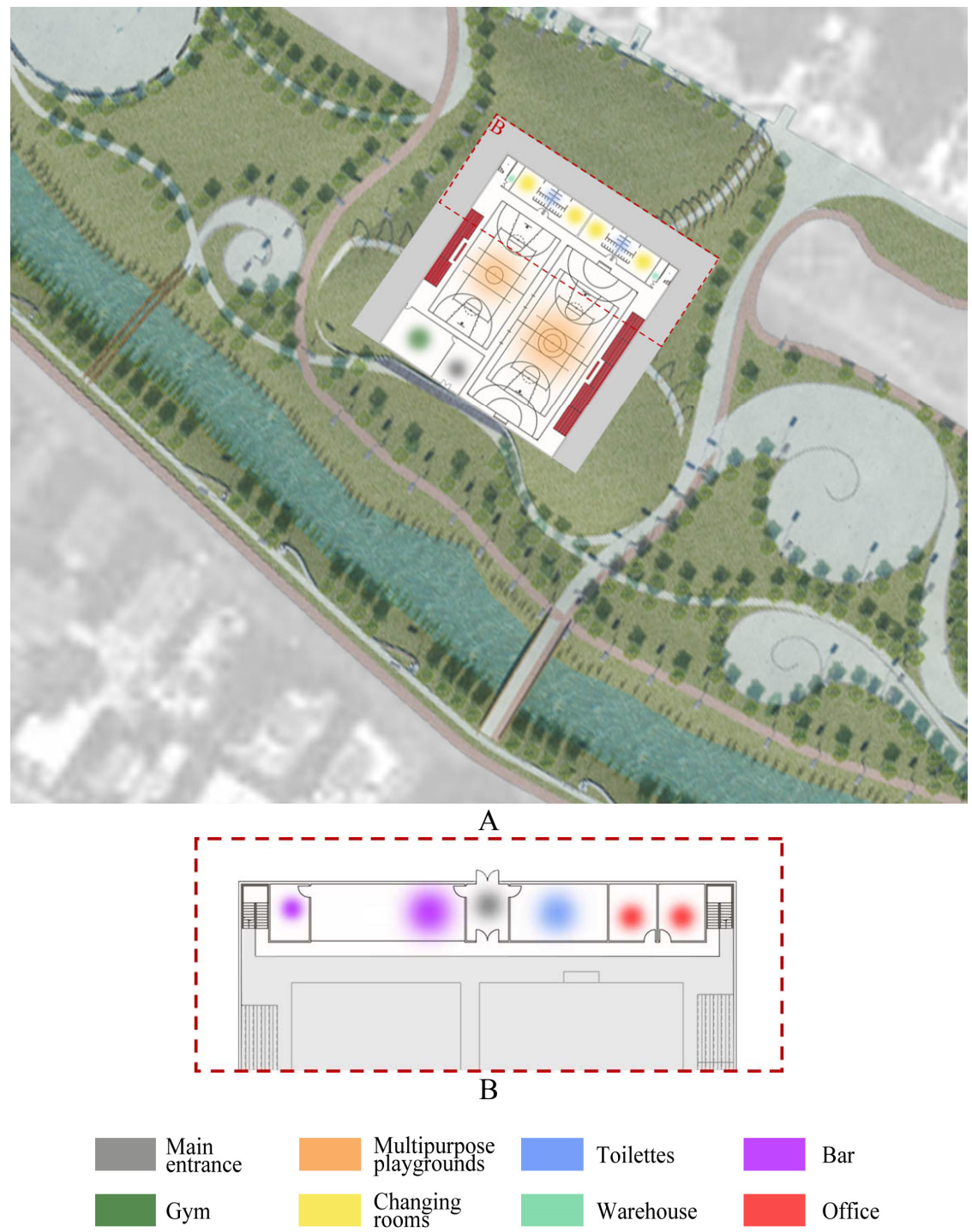

Figure 5: Plan of the sport center - A: ground floor; B: first floor.

The building is based on the concept of high energy saving: the glass wall guarantees thermal and acoustic insulation, electric power is mostly supplied by the photovoltaic system, led lighting is used [8], a recovery water system is present in both the two structure floors.

The glass of the south-west glass wall, has been chosen for its features: hydrophobic, self-cleaning, anti-reflective and anti-fogging. It avoids problems related to glare and high maintenance costs for cleaning. 
Considering clean energy production for reducing greenhouse gas emissions [9], the main entrance to the sport center is shaded by photovoltaic glass canopy due to the high solar radiation in its orientation (Figure 6B).

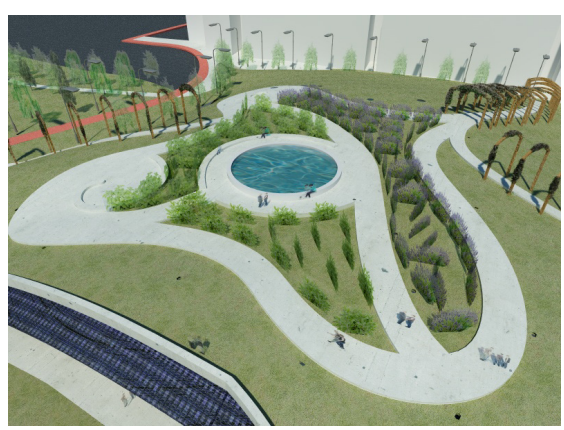

A

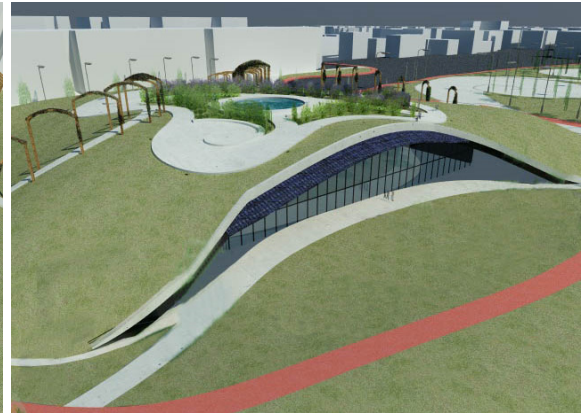

B

Figure 6: A: sensory path; B: green roof and PV plant on the sport centre main entrance.

This system of $10 \mathrm{kWp}$ supplies energy for outdoor lighting and for ten neighboring charging points for electric bike, and involves an annual saving of $5.841 \mathrm{~kg}$ of $\mathrm{CO}_{2}$.

Moreover, a dedicated gas trigeneration system is installed in the lower floor providing $154.42 \mathrm{kWt}$ for heating and hot water and $51.47 \mathrm{kWe}$ for electrical supplies.

Furthermore, considering the water sustainability, the installation of rainwater recovery device allows to purify and reuse it for flushing the toilet and watering plants in the sensory pathways.

Rainwater comes from photovoltaic glass canopy and from all the cemented areas of the sensory pathways. The latter are draining, composed of an innovative formulation of concrete combined with specific sub-services for eliminating oils and other contaminants that would make the water more difficult to purify.

The recovered water is collected in two tanks positioned in opposite sides of the building, camouflaged by the steep terrain; this recycling of water is also applied to the sinks and showers in the locker room allowing significant savings of water.

The floors consist of a special anti-smog and antibacterial ceramic based on titanium dioxide that, due to exposure to natural or artificial light, activates a strong oxidative process that leads to the decomposition of organic substances and inorganic pollutants that come into contact with the photocatalytic surfaces. Even wall painting allows the photocatalytic reduction of pollutants and the reduction of unpleasant odors.

Lastly, the gym area includes special machines such as treadmills, exercise bikes, steppers, which use the kinetic energy produced during their use for supplying monitors and music equipment in the same gym: with 30 active 
machines working about 8 hours a day, the estimated self-produced energy comes to cover as much as $25 \%$ of the energy needs of a wellness and fitness center.

\section{Green area requalification}

The interventions described aim to enhance the landscape and environmental quality through the inclusion of pedestrian and cycle paths connected to existing ones through new wooden bridges.

Pedestrian paths use nanotechnology system in order to strengthen dirt patch with high levels of resistance and limited maintenance.

Nanotechnology system is based on the use of particles of silicates; it is an efficient alternative to the traditional construction techniques for pedestrian and cycling lane foundations [10].

This technology leads to many benefits:

- the realization of stable and long-lasting layers, able to stand dynamic loads even in the case of problematic substrates;

- a high weather resistance, low shrinkage, absence of dehydration, greater load, frost resistance and durability;

- lower shutter speeds and lower installation costs compared to traditional interventions; reduction of maintenance costs.

In order to create a connection between the park area and surrounding buildings, the existing road has been switched in a tunnel for vehicular traffic.

Winding paths define areas for specific purpose such as dogs agility courses, outdoors fitness, children games, amphitheater (Figure 7A) and horticulture therapy.

Dogs agility area includes bench for hosts, drinking fountains and water bowl for dogs.

Jogging and many other sporting activities can be performed both in closed and open place using the sport center or public open space with free sport equipment.

Kids play area has an innovative anti trauma flooring; that can reduce safety issues in public play spaces, in compliance with European standards (UNI EN 1177); these flooring materials are made of recycled plastics, rubber and tires.

Horticultural therapy includes activities such as gardening, growing plants and vegetables and the care of a dedicated plant (Figure 7B) $[11,12]$.

The choice of the area for the horticultural therapy comes from the presence of fruit trees planted by local inhabitants.

In the park an integrated smart lightning system was added that allows timed lighting, low level of light pollution of the paths and a wi-fi coverage in the whole area; there are even security systems and video surveillance integrated. 


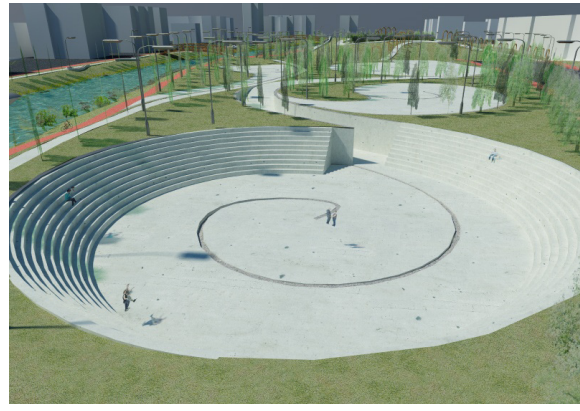

A

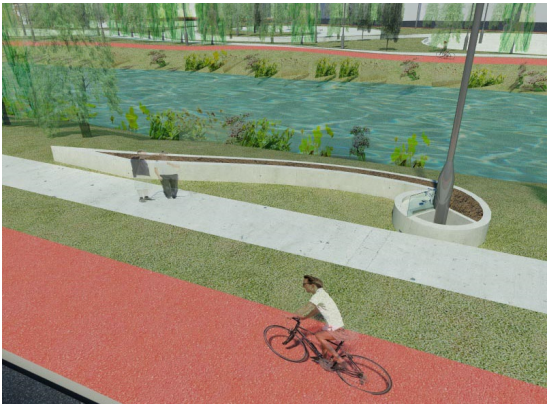

B

Figure 7: A: amphitheater design; B: horticultural therapy area.

\section{Bioengineering for ecological sustainability}

Considering the ecological requalification of the considered park, the project aims to the implementation of ecological corridors for those species whose natural habitats include the surrounding areas [13].

Moreover, using particular expedients it is possible to improve the reduction of environmental pollution due to the presence of green areas in urban settlements.

This would be possible by the conservation and requalification of the riparian ecosystems along the river banks.

This kind of management was obtained through the use of bioengineering techniques finalized to anti-erosion, flood protection and river bed modelling works, with particular attention to the rehabilitation of natural riparian habitats [14].

In particular, bioengineering techniques such as include coir fiber rolls, brush mattress, erosion control blankets, geotexile coir mats and vegetated rock walls, provide a surface protection of the river banks against erosion from current, weather and runoff water allowing at the same time the development of new ecosystemic units.

Considering the choice of vegetation type and plant species, the planning intervention was preceded by an analysis of local natural habitat in order to favours planting of endemic species, absolutely avoiding the use of alien and allochthonous plants.

Using the "ecosystem approach" modus operandi, described by the Conference of the Parties of the CBD (Convention on Biological Diversity) [15], the project foresees the planting of native species for the conservation and requalification of local habitats. In particular, the project includes the planting of trees for the optimization of its environmental sustainability, considering those species particularly indicated for the mitigation of atmospheric pollution thanks to the roughness and largeness of their leafs which facilitate the absorption of particular matters (PM10), heavy metals and other air pollutants. 
These benefits are optimised by planting trees with rough foliage, such as Ostrya carpinifolia, Ulmus spp., Carpinus betulus, and Quercus pubescences. Moreover, planting trees like Platanus spp., Cupressus spp. and Taxus spp. give better results in SOx adsorption, while the choose of Acer campestre and Quercus robur favours the same effects on fluorides.

Considering bioclimatic aspects, the choice of tree species with high foliage density in the warm periods and low level of shading in the cold season provides cooling in summer and heating in the winter months; trees are also foresee for the reduction of winter wind speed in certain areas of the park in order to improve the well-being of the users.

Last but not least, good environmental quality and biodiversity presence in urban areas involve advantages for quality of life, human health and wellbeing, with benefits on the physical and mental status of citizens [16].

\section{Conclusions}

The park requalification described in this paper improved environmental sustainability, human health and well-being in terms of social and antropic benefits, such as facilitation of sport and green exercise activities, social networking and improving of aesthetic values of the quarter and the whole town.

The theme of the integration between architecture and nature as well as the environmental sustainability permeates the entire planning, going through each project aspect, looking for constructive solutions that maximize the well-being of the users and the overall quality of the whole environment. The park should be considered an element of connection between urban built areas and natural elements. Moreover, thanks to its position, this area is very important for the improvement of the sustainable mobility in the city, especially for the pedestrian and cycle paths and for the two wheels electric mobility.

\section{References}

[1] Cumo, F., Astiaso Garcia, D., Calcagnini, L., Rosa, F., Sferra, A.S., 2012. Urban policies and sustainable energy management. Sustainable Cities and Society 4 (1), pp. 29-34.

[2] Ippolito A. M., L'archinatura. Le diverse modalità di dialogo dell'architettura con la natura, Angel F., 2010.

[3] Dunnet N.P. and Kingsbury N., 2004. Planting green roofs and living walls. Portland, Timber Press.

[4] Velasquez L. S., 2005. Organic greenroof architecture: design considerations and system components. Environmental Quality Management (Summer).

[5] Cumo, F., Cinquepalmi, F., Pennacchia, E., Sforzini, V., 2012. High performing building as a pier for sustainable tourism in the protected area of Bracciano Lake in Italy. WIT Transactions on Ecology and the Environment 165, pp. 175-182. 
[6] Cinquepalmi, F., Cumo, F., Gugliermetti, F., Sforzini, V., 2010. Advanced technologies for sustainable building in the protected areas: Two case studies in Italy, WIT Transactions on Ecology and the Environment, 128, pp. 551-560.

[7] Peng, H.K., 2014. On the eco-building for sustainable development thinking and practising environmental design. Applied Mechanics and Materials 448-453, pp. 1325-1328.

[8] Jin, D., Goldbach, S., 2014. Enabling (bio) materials: Feasibility study for its implementation in development of sustainable lighting product. Key Engineering Materials 572 (1), pp. 58-61.

[9] Astiaso Garcia, D., Cinquepalmi, F., Cumo, F., 2013. Air quality in Italian small harbours: a proposed assessment methodology. Rendiconti Lincei, 24(4), pp. 309-318.

[10] Astiaso Garcia, D., Cumo, F., Sforzini, V., Albo, A. 2012. Eco friendly service buildings and facilities for sustainable tourism and environmental awareness in protected areas. WIT Transactions on Ecology and the Environment 161, pp. 323-330.

[11] Gonzalez, M.T., Kirkevold, M., 2013. Benefits of sensory garden and horticultural activities in dementia care: A modified scoping review. Journal of Clinical Nursing.

[12] October, J.R.V., De Villiers, A., Dolley, L., 2013. The design of a horticultural therapy model and a practical business plan for a horticulturist interacting with a healthcare worker. Acta Horticulturae 1007, pp. 503-512.

[13] Astiaso Garcia, D., Bruschi, D., Cinquepalmi, F., Cumo, F. 2013. An estimation of urban fragmentation of natural habitats: Case studies of the 24 Italian national parks. Chemical Engineering Transactions 32, pp. 49-54.

[14] De Santoli L., Astiaso Garcia D. and Violante A.C., 2008. Planning of flood defence management and rehabilitation of the natural habitat in the downstream part of the river Tiber". Geo-Environment and Landscape Evolution III. WIT Transaction on the Built Environment Vol 100. WIT Press, pp 25-34.

[15] Vasishth A. and Sloane D.C., 2003. Returning to Ecology: An Ecosystems Approach to Understanding the City. in Dear, M J (ed) Chicago to LA: Making Sense of Urban Theory, Thousand Oaks. Sage Publications.

[16] Chiesura A., 2004. The role of urban parks for the sustainable city. Landscape and Urban Planning, 68, pp. 129-38. 